\title{
Effect of fruit pulp supplementation on rapid and enhanced ethanol production in very high gravity (VHG) fermentation
}

\author{
Veeranjaneya Reddy Lebaka ${ }^{1 *}$, Hwa-Won Ryu ${ }^{2}$ and Young-Jung Wee ${ }^{3}$
}

\begin{abstract}
Background: The energy crisis and climate change necessitate studying and discovering of new processes involved in the production of alternative and renewable energy sources. Very high gravity (VHG) fermentation is one such process improvement aimed at increasing both the rate of fermentation and ethanol concentration. The technology involves preparation and fermentation of media containing $300 \mathrm{~g}$ or more of dissolved solids per liter to get a high amount of ethanol.

Findings: Saccharomyces cerevisiae was inoculated to the very high gravity medium containing 30\% to $40 \% \mathrm{~W} / \mathrm{V}$ glucose with and without supplementation of three selected fruit pulps (mango, banana, and sapota). The fermentation experiments were carried out in batch mode. The effect of supplementation of $4 \%$ fruit pulp/puree on the metabolic behavior and viability of yeast was studied. Significant increase in ethanol yields up to $83.1 \%$ and dramatic decrease in glycerol up to 35\% and trehalose production up to 100\% were observed in the presence of fruit pulp. The fermentation rate was increased, and time to produce maximum ethanol was decreased from 5 to 3 days with increased viable cell count. The physical and chemical factors of fruit pulps may aid in reducing the osmotic stress of high gravity fermentation as well as enhanced ethanol yield.

Conclusions: It was found that fruit pulp supplementation not only reduced fermentation time but also enhanced ethanol production by better utilization of sugar. Production of high ethanol concentration by the supplementation of cheap materials in VHG sugar fermentation will eliminate the expensive steps in the conventional process and save time.
\end{abstract}

Keywords: High gravity fermentation; Osmotic stress; Ethanol; Fruit pulp supplementation

\section{Background}

The energy crisis and climate change necessitate studying and discovering of new processes involved in the production of alternative and renewable energy sources. Bioethanol is regarded as a promising alternative energy source, which is both renewable and environmentally friendly $[1,2]$. The commonly used ethanol producer in industries is Saccharomyces cerevisiae and the initial sugar concentration will not exceed $20 \%$ and the conventional ethanol production process needs high energy, high cost and low productivity [3]. Very high gravity (VHG) fermentation is one such process improvement

\footnotetext{
* Correspondence: Ivereddy@yahoo.com

'Department of Microbiology, Yogi Vemana University, Kadapa, Andhra Pradesh 516003, India

Full list of author information is available at the end of the article
}

aimed at increasing both the rate of fermentation and ethanol concentration. The technology involves preparation and fermentation of media containing $300 \mathrm{~g}$ or more of dissolved solids per liter [4]. VHG fermentation influences the five basic fermentation assets: (1) plant and equipment, (2) raw materials, (3) utilities and consumables, (4) personnel, and (5) money [5]. High gravity fermentation is an accepted method to produce more ethanol in existing fermenters and distil houses (affecting item 1), and uses less cooling equipment and produces less effluent (affecting item 3), resulting in higher yield (affecting item 2) and less staff work (affecting item 4); all these properties decrease the money investment for ethanol production. Another advantage is an increase in opportunities for harvest of high protein spent yeast $[4,6]$. 
However, the high sugar content of the very high gravity fermentation medium causes an increase in the osmotic pressure, which has a pessimistic effect on yeast cells, and the fermentations are rarely fast and complete. The ethanol produced by the yeast also poses negative effects on yeast metabolism like enzyme inhibition and membrane solubility and needs some protectants to counteract these effects at the end of the fermentation process [3]. S. cerevisiae can ferment an increased amount of sugars in the medium when all required nutrients are provided in adequate amounts [6]. Specific nutrients, such as nitrogen, trace elements, or vitamins, are required to obtain rapid fermentation and high ethanol levels, which are desirable to minimize capital costs and distillation energy. On a laboratory scale, media are often supplemented with peptone, yeast extract, amino acids, and vitamins [6-8]. However, such addition is not feasible in industrial fermentation processes due to the associated high costs. Thus, it is necessary to exploit inexpensive nutrient sources to supply all nutritional requirements for yeast growth and fermentation. Many investigators studied the effect of inexpensive substances like soy flour, oils and fatty acids, fungal mycelia, and fruit pulp [9-12] on the improvement of ethanol production. In our laboratory, we have tested finger millet and horse gram powder supplementation in VHG fermentation and successfully improved the ethanol production $[13,14]$.

In view of the above, we have screened 15 different commercially available fruits to determine their effect on very high gravity fermentation in terms of fermentation rate and enhancement of ethanol yield. In this paper, we presented the results of tropical fruit pulps mango (Mangifera indica), banana (Musa paradisiaca), and sapota (Achras sapota), which show a significant effect in enhancing the ethanol production during the screening process.

\section{Materials and methods \\ Organism and cultural conditions}

Yeast strain S. cerevisiae 3215 was used in all the experiments. The yeast strain was obtained from National Collection of Industrial Microorganisms (NCIM, Pune, India). The culture was maintained on MPYD (malt extract $3 \mathrm{~g} / \mathrm{L}$, peptone $5 \mathrm{~g} / \mathrm{L}$, yeast extract $3 \mathrm{~g} / \mathrm{L}$, and dextrose $2 \mathrm{~g} / \mathrm{L})$ agar $(1.5 \mathrm{~g} / \mathrm{L})$ slants at $4^{\circ} \mathrm{C}$. The inoculum was prepared by inoculating the slant culture into $25 \mathrm{~mL}$ of the sterile MPYD liquid medium taken in a $100-\mathrm{mL}$ flask and growing it on a rotary shaker $(100 \mathrm{rpm})$ for $48 \mathrm{~h}$. The above produced yeast culture $\left(5 \%, 1 \times 10^{6}\right.$ cells $\left./ \mathrm{mL}\right)$ was used as inoculum to initiate the fermentation.

\section{Fruit pulp preparation for supplementation}

The fruits selected for the supplementation, mango ( $M$. indiaca), banana (M. praradisiaca), and sapota (A. sapota), were purchased from the local market of Kadapa, India. The fruits were peeled off, and the pulp was separated from stones in the case of mango and sapota and prepared as puree with a macerator. The prepared puree will have good suspension in the fermentation medium.

\section{Fermentation}

The very high gravity fermentation medium composition is the same as the abovementioned MPYD medium with high glucose concentration (300 to $400 \mathrm{~g} / \mathrm{L}$ ); $4 \%$ fruit pulp/puree was supplemented to 300 and $400 \mathrm{~g} / \mathrm{L}$ sugar medium to evaluate the potential effect of fruit pulps in enhancing the ethanol production, and the medium without supplementation of fruit pulp was treated as control. Fermentations were conducted at $30^{\circ} \mathrm{C}$ in $250-\mathrm{mL}$ Erlenmeyer flasks with $100 \mathrm{~mL}$ of fermentation medium. The initial $\mathrm{pH}$ was adjusted to 5.5. The progress of fermentation was monitored by periodical sample analysis. The fermentation was stopped after 5 days, and samples were kept at $-4^{\circ} \mathrm{C}$ until the analysis.

\section{Analytical estimations}

Sugar concentration was estimated using the Shaffer and Somogyi method [15] as follows: Reducing sugars were estimated using the idometric method of Shaffer and Somogyi (1933). Sugars containing a free sugar syrup group undergo enolization when placed in an alkaline solution. Enediol forms of sugars are highly reactive to acids. The reduced copper was quantified by idometric titration using starch as an indicator. The $1 \mathrm{~L}$ reagent contains sodium carbonate (25 g), Rochelle salt (25 g), copper sulfate $(75 \mathrm{~mL}$ from $100 \mathrm{~g} / \mathrm{L}$ solution), sodium bicarbonate $(20 \mathrm{~g})$, potassium iodide $(5 \mathrm{~g})$, and potassium iodate $(3.567 \mathrm{~g})$. A $5 \mathrm{~mL}$ solution containing 0.5 to $2.5 \mathrm{mg}$ dextrose units was pipetted into test tubes and $5 \mathrm{~mL}$ of reagent was added; then, the solution with the added reagent was mixed well by stirring. Tubes capped with bulbs were placed in a boiling water bath for $15 \mathrm{~min}$ and cooled under running water. Next, $2 \mathrm{~mL}$ of idodine-oxalate titrated with $0.005 \mathrm{~N}$ sodium thiosulfate was added using starch as indicator. Ethanol was determined with the help of gas chromatography [16]. The fermented samples were centrifuged at $5,000 \mathrm{rpm}$ for $10 \mathrm{~min}$. The supernatant was used for ethanol analysis. An Agilent Systems Gas Chromatograph with Flame Ionization Detector (GC-FID) Model 6890 Plus instrument (Agilent Technologies Inc., Santa Clara, CA, USA) was used, and conditions were as follows: $5 \%$ Carbowax 20M glass column (6 ft (2 m), 2-mm inner diameter (ID), $1 / 4 \mathrm{~mm}$ ). Nitrogen was used as a carrier gas with a flow of $20 \mathrm{~mL} / \mathrm{min}$, and the eluted compounds were detected using a flame ionization detector (FID). For this, the fuel gas was hydrogen with a flow rate of $40 \mathrm{~mL} / \mathrm{min}$, and the oxidant was air with a flow rate of $40 \mathrm{~mL} / \mathrm{min}$; $n$-propanol was used as internal 
standard. Glycerol on diluted samples was estimated using Boehringer kits (Boehringer Mannheim (Roche, Basel Switzerland); enzymatic test $(340 \mathrm{~nm}) 3 \times 11$ determinations (code number 10148270035)). Trehalose was estimated in the supernatant by the anthrone method as described previously [17]. The pellet obtained after the trehalose extraction was used for the protein estimation.

\section{Cell viability}

Cellular viability was determined by the methylene blue staining technique [18]. A $100 \mathrm{~mL}$ sterile solution of methylene blue ( $3.3 \mathrm{mM}$ in $68 \mathrm{mM}$ sodium citrate) was mixed with $100 \mathrm{~mL}$ of a yeast suspension diluted to reach an OD of 0.4 to 0.7 at $620 \mathrm{~nm}$. This mixture was shaken, and after a 5-min incubation, it was placed in a Thomas counting chamber. The number of stained (inactive cells) and unstained (active cells) were counted in five different fields with total of at least 200 to 300 cells.

\section{Statistical analysis}

All the experiments were carried out three times (triplicate), and the mean value with standard deviation and significant $(P)$ was determined. SPSS version 11.0 was used for analysis of variance.

\section{Results}

The present study provides potential observation of fruit pulps as supplements in small quantity during fermentation stimulating the rate of alcohol production and final alcohol concentration in very high gravity fermentation. Two sets of batch fermentation experiments with two levels of sugar concentrations, 300 and $400 \mathrm{~g} /$ L (30\% and 40\%), were carried out with and without fruit pulp supplementation, in order to evaluate the effect of fruit pulps. The unsupplemented batch fermentation experiments yielded only 9\% $(w / v)$ of alcohol in $300 \mathrm{~g} / \mathrm{L}$, and a good amount of residual sugars was left and incompletely fermented by S. cerevisiae. However, the $4 \%$ fruit pulp supplementation led to a significant increase in ethanol production, and the final concentration reached $14.5 \%(w / v)$ in a shorter time $(72 \mathrm{~h})$ with a productivity of $2.1 \mathrm{~g} / \mathrm{h} / \mathrm{L}$ (Table 1 ). In the three fruit pulps selected, mango supplementation gave the highest yields of ethanol when compared to banana and sapota. In the fruit pulp-supplemented medium, 10\% $(v / v)$ of ethanol production was achieved in just $48 \mathrm{~h}$ after the inoculation. Besides the high fermentation rate in the supplemented medium, it also decreased the duration of fermentation from 5 to 3 days.

An attempt was made to increase ethanol production up to $18 \%$ to $20 \%(w / v)$ as in the case of sake fermentation, by increasing the sugar concentration from 300 to $400 \mathrm{~g} / \mathrm{L}$ with supplementation of fruit pulp. In the $400 \mathrm{~g} / \mathrm{L}$ sugar fermentation with $4 \%$ fruit pulp supplementation, the ethanol concentration was $12.5 \%$ (Table 1). The sugars were utilized maximally up to $300 \mathrm{~g} / \mathrm{L}$. In the three fruit pulps selected, mango supplementation gave the highest yields of ethanol when compared to banana and sapota. The ethanol production after 5 days in the control experiments was only $7.5 \%$.

\section{Effect of fruit pulp supplementation on cell viability}

After 30 to $35 \mathrm{~h}$ of fermentation in both supplemented and control media, cell growth rate was decreased. After 40 to $50 \mathrm{~h}$, the growth ceased, but glucose fermentation continued slowly until the number of the viable cell count decreased and became very low. The viability percentage of yeast cells in the supplemented medium was greater than that in the control medium. The supplementation of fruit pulp led to an increase in the rate of fermentation and ethanol yield through the extended growth phase of cells (Figure 1). In the three fruit pulps selected, mango supplementation gave a higher cell viability than banana and sapota supplementation.

Table 1 Effect of fruit pulp supplementation on ethanol production in $\mathbf{3 0}$ and $\mathbf{4 0 \%}$ sugar fermentation

\begin{tabular}{|c|c|c|c|c|c|c|c|c|}
\hline & \multirow[t]{2}{*}{ Serial number } & \multirow[t]{2}{*}{ Supplement } & \multicolumn{6}{|c|}{ Alcohol concentration (w/v) } \\
\hline & & & $24 \mathrm{~h}$ & \% IMP & $48 \mathrm{~h}$ & \% IMP & $72 \mathrm{~h}$ & $\%$ IMP \\
\hline \multirow[t]{4}{*}{$30 \%$ Sugar } & 1 & Control & $2.5 \pm 0.3$ & - & $5.5 \pm 0.3$ & - & $9.0 \pm 0.7$ & - \\
\hline & 2 & Mango & $4.5 \pm 0.5$ & $90 \pm 4.5$ & $10 \pm 0.8$ & $90.5 \pm 8.0$ & $14.5 \pm 1.2$ & $80.5 \pm 10$ \\
\hline & 3 & Banana & $4.0 \pm 0.5$ & $80 \pm 4.0$ & $9.0 \pm 1.0$ & $81.5 \pm 9.0$ & $13.2 \pm 1.0$ & $73.1 \pm 8.0$ \\
\hline & 4 & Chiku & $4.0 \pm 0.4$ & $80 \pm 4.2$ & $7.5 \pm 0.6$ & $68 \pm 6.2$ & $12 \pm 0.8$ & $66.5 \pm 4.8$ \\
\hline \multirow[t]{4}{*}{$40 \%$ Sugar } & 1 & Control & $2.0 \pm 0.3$ & - & $4.5 \pm 0.5$ & - & $7.5 \pm 0.6$ & - \\
\hline & 2 & Mango & $4.0 \pm 0.2$ & $100 \pm 2.0$ & $8.4 \pm 0.7$ & $93 \pm 7.0$ & $12.5 \pm 1.0$ & $83.3 \pm 10$ \\
\hline & 3 & Banana & $3.3 \pm 0.3$ & $82.5 \pm 2.5$ & $8.0 \pm 0.6$ & $87.6 \pm 6.2$ & $11 \pm 0.8$ & $73.3 \pm 7.0$ \\
\hline & 4 & Chiku & $3.2 \pm 0.2$ & $77.5 \pm 2.0$ & $7.2 \pm 0.8$ & $80 \pm 6.8$ & $10 \pm 1.0$ & $66.5 \pm 8.1$ \\
\hline
\end{tabular}




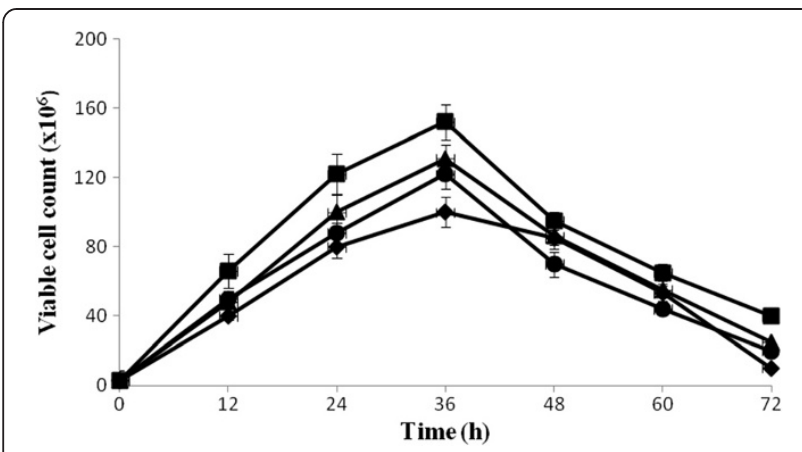

Figure 1 Effect of fruit pulp supplementation on yeast cell viability in $\mathbf{3 0} \%$ sugar fermentation. Diamond, control; square, mango; triangle, banana; circle, sapota.

\section{Effect of fruit pulp supplementation on glycerol production and trehalose}

Concentrations of glycerol, one of the stress indicators and releasers, were decreased in the fruit pulp-supplemented experiments from 954 to $620 \mathrm{mg} / \mathrm{L}$ in the $300 \mathrm{~g} / \mathrm{L}$ fermentation and from 1,266 to $823 \mathrm{mg} / \mathrm{L}$ in the $400 \mathrm{~g} / \mathrm{L}$ fermentation (Table 2). In the three fruit pulps selected, mango supplementation gave less glycerol when compared to banana and sapota supplementation. Trehalose is a disaccharide which is typically produced by yeast when it experiences stress conditions. In the present study, trehalose concentration was in low in the fruit pulpsupplemented experiments when compared to the unsupplemented control experiments (Table 3 ). In the control $30 \%(w / v)$ fermentation experiments, the trehalose concentration was $40 \mathrm{mg} / \mathrm{g}$ yeast cells, and in the fruit pulpsupplemented experiments, it was $21 \mathrm{mg} / \mathrm{g}$ yeast cells. In the $40 \%$ sugar $(w / v)$ control fermentation experiments, the trehalose concentration was $52 \mathrm{mg} / \mathrm{g}$ yeast cells, while in the fruit pulp supplementation with aeration experiments, it was $38 \mathrm{mg} / \mathrm{g}$ yeast cells. In the three fruit pulps selected, mango supplementation decreased the trehalose to low levels when compared to banana and sapota supplementation.

\section{Discussion}

The present study provides potential observation of fruit pulps as supplements in small quantity during fermentation

Table 2 Effect of fruit pulp supplementation on glycerol production in $\mathbf{3 0}$ and $\mathbf{4 0 \%}$ sugar fermentation

\begin{tabular}{|c|c|c|c|c|}
\hline \multirow{2}{*}{$\begin{array}{l}\text { Serial } \\
\text { number }\end{array}$} & \multicolumn{2}{|l|}{$30 \%$ Sugar } & \multicolumn{2}{|l|}{$40 \%$ Sugar } \\
\hline & Supplement & Glycerol (mg/L) & Supplement & Glycerol (mg/L) \\
\hline 1 & Control & $954 \pm 62$ & Control & $1,266 \pm 75$ \\
\hline 2 & Mango & $620 \pm 35$ & Mango & $823 \pm 54$ \\
\hline 3 & Banana & $757 \pm 58$ & Banana & $938 \pm 68$ \\
\hline 4 & Chiku & $826 \pm 73$ & Chiku & $1,040 \pm 47$ \\
\hline
\end{tabular}

stimulating the rate of alcohol production and final alcohol concentration in very high gravity fermentation. In unsupplemented controls of $30 \%$ glucose fermentation experiments, compared with the supplemented medium, the sugar was not utilized completely. It is evident that at the end of fermentation, yeast requires certain nutrients that aid tolerance to the high concentrations of alcohol it forms. Nearly $70 \%$ to $75 \%$ of the volume of the final ethanol concentration was formed within $48 \mathrm{~h}$ of fermentation, and almost all the final concentration of ethanol was formed in $60 \mathrm{~h}$; the remaining $1 \%$ or $2 \%(v / v)$ took some time for its secretion out of the cell. In addition to nutrients, fruit pulps also contain good amounts of polyphenols (all flavones, stilbenes, flavonones, isoflavones, catechins, chalcones, tannins, and anthocyanidins), which are frequently attributed to antioxidant, metal ion-chelating, and/or free radical scavenging activity [19]. This may help in keeping the yeast cells viable for longer duration and producing such high concentrations of ethanol in $48 \mathrm{~h}$. The supplemented medium had higher viable cell count than the control medium. There was a dramatic drop in cell count from $10 \times 10^{7}$ to $3 \times 10^{7}$ in the control medium with increase in ethanol concentration from $5 \%$ to $9 \%(v / v)$. But in the supplemented medium, the cell viability went up even up to $12 \%(v / v)$ ethanol. This indicates that the threshold concentration of ethanol to yeast inhibition is $9 \%(v / v)$. In all cases, the cell viability increased even at high ethanol concentration $(12 \% v / v)$ in the fruit pulp-supplemented medium compared with the control medium. Alfenore et al. [6] made a similar observation in fed-batch fermentation by vitamin feeding strategy that enhanced the final ethanol up to $19 \%(v / v)$ in $45 \mathrm{~h}$.

The important byproduct formed during ethanol fermentation is glycerol. Commonly, its production is high in high gravity fermentation. Glycerol is the well-known compatible solute in $S$. cerevisiae. Osmophilic yeasts accumulate glycerol to compensate for high osmotic pressure $[20,21]$. In the present study, the formation of glycerol was found to be high at the growth/logarithmic phase. After cessation of cell growth, glycerol was not present much in the media. The percentage of glycerol in the supplemented media was low when compared with that in the control medium. These results confirmed the previous reports that the growth rate of yeast cells is reduced irreversibly in proportion to an increase in external osmolarity [21]. Another important reserve carbohydrate and stress protectant for the yeast is trehalose. Trehalose is also considered as one of the most effective saccharines in preventing phase transition in the lipid bilayer and thereby protecting membranes against damages, and considering the relation of intracellular trehalose concentration with the cellular resistance to osmotic stress, trehalose was supposed to act as an osmoprotectant under osmotic stress [20]. In the supplemented medium, trehalose concentration was 
Table 3 Effect of fruit pulp supplementation on trehalose accumulation in $\mathbf{3 0}$ and $\mathbf{4 0 \%}$ sugar fermentation

\begin{tabular}{|c|c|c|c|c|}
\hline \multirow[t]{2}{*}{ Serial number } & \multicolumn{2}{|l|}{$30 \%$ Sugar } & \multicolumn{2}{|l|}{$40 \%$ Sugar } \\
\hline & Supplement & Trehalose (mg/g yeast cells) & Supplement & Trehalose (mg/g yeast cells) \\
\hline 1 & Control & $40 \pm 3.4$ & Control & $52 \pm 2.5$ \\
\hline 2 & Mango & $21 \pm 2.8$ & Mango & $38 \pm 3.2$ \\
\hline 3 & Banana & $29 \pm 3.3$ & Banana & $43 \pm 4.6$ \\
\hline 4 & Chiku & $34 \pm 2.6$ & Chiku & $49 \pm 3.8$ \\
\hline
\end{tabular}

decreased at the end of the fermentation which shows that the cells are not under stress when compared to the control. This could explain the fact that stress induced the genes involved in trehalose synthesis and those involved in degradation, and why the genes responded in a similar pattern in osmotic and oxidative stress [22]. It has been reported that the production pattern of protein synthesis is changed dramatically by osmotic and heat stress, and also depriving amino acids or proteins inhibits translation initiation through the phosphorylation pathway $[23,24]$.

Higher amount of ethanol in the $400 \mathrm{~g} / \mathrm{L}$ sugar medium was not obtained probably due to the initial high glucose concentration that strongly inhibited fermentation. Even in such high osmolarity, the supplemented media yield $12.5 \%(v / v)$ ethanol with a productivity of $1.73 \mathrm{~g} / \mathrm{h} / \mathrm{L}$. It is likely that the supplementation of fruit pulp may add sugars, thereby contributing to the increased osmotic pressure. The old yeast cells ferment slowly when compared with actively growing yeast cells. It is possible to produce high ethanol concentrations by extending the growth phase of yeast to longer periods as in the case of beer production. It is expected that fruit pulp supplementation would overcome nutritional deficiencies of yeast and allow them to stay longer in the growth phase and that antioxidants protected the yeast cells from osmotic stress and aeration allowed yeast to produce membrane lipids to be sustained at higher alcohol concentrations. During VHG ethanol fermentation, maintaining the redox potential at a constant level is essential, as yeast requires a small amount of oxygen to facilitate the synthesis of sterols and unsaturated fatty acids, which serve as the building blocks for constructing cell membranes [25].

\section{Conclusions}

It is concluded that fruit pulp supplementation enhanced the rate and yield of ethanol production in a very high gravity medium. It is observed that the selected fruit pulps were not much effective in the $400 \mathrm{~g} / \mathrm{L}$ sugar fermentation when compared to the $300 \mathrm{~g} / \mathrm{L}$ sugar fermentation. The decrease in both glycerol and trehalose concentrations by the supplementation would suggest that the fruit pulp constituents might be involved in lowering the osmotic stress induced by high sugar at the beginning of fermentation and high ethanol stress at the end of the fermentation. The increased ethanol production by the fruit pulp supplementation is a significant finding that could also be applied to an industrial fermentation of ethanol utilizing molasses and other raw materials as substrates. This may reduce the cost of ethanol production in developing countries like India. The nature of active principles from fruit pulps and their mechanism that aids in tolerating high osmotic stress and enhance ethanol production rate are being investigated by the authors.

\section{Abbreviations}

\% IMP: percentage of improvement; \%: percent; g/l: gram per liter; mg/ I: milligram per liter; mM: millimolar; MPYD: malt extract, peptone, yeast extract, and dextrose (medium); v/v: volume per volume; VHG: very high gravity; $w / v$ : weight per volume.

\section{Competing interests}

The authors declare that they have no competing interests.

\section{Authors' contributions}

LV participated in the design of the study, carried out the fermentations, analyzed the results, and wrote the manuscript. YJ participated in the experimental procedure and the GC and result analysis. HW conceived the study and participated in analyzing the results and correcting the manuscript. All authors read and approved the final manuscript.

\section{Acknowledgements}

The author would like to acknowledge the Council of Scientific and Industrial Research, Government of India and Department of Science and Technology, Government of India for the financial support given in the form of research projects entitled 'Studies on Rapid and Enhanced Production of Ethanol through Very High Gravity (VHG) Fermentation' (Ref No: 38 (1310)/ 11/EMR-II) and 'Biotechnological production of Acetone-Butanol-Ethanol (ABE) from agricultural biomass using solventogenic bacteria' (Ref No: SR/FT/ LS-79/2009).

\section{Author details}

'Department of Microbiology, Yogi Vemana University, Kadapa, Andhra Pradesh 516003, India. ${ }^{2}$ School of Biological Sciences and Technology, Chonnam National University, Gwangju 500-757, Korea. ${ }^{3}$ Department of Food Science and Technology, College of Natural Resources, Yeungnam University, Gyeongbuk 712-749, Korea.

Received: 22 July 2014 Accepted: 19 October 2014

Published online: 15 November 2014

\section{References}

1. Cardona C, Sa'nchez O (2007) Fuel ethanol production: process design trends and integration opportunities. Bioresour Technol 98:2415-2457

2. Reddy LVA (2013). Potential bioresources as future sources of biofuels production: an overview. V. K. Gupta and M. G. Tuohy (eds.), Biofuel technologies, SpringerVerlag Berlin Heidelberg doi:10.1007/978-3-642-34519-7_9, 2013 
3. Pereira FB, Guimarães PMR, Teixeira JA, Domingues $L$ (2010) Optimization of low-cost medium for very high gravity ethanol fermentations by Saccharomyces cerevisiae using statistical experimental designs. Bioresour Technol 101:7856-7863

4. Thomas KC, Hynes SH, Jones AM, Ingledew WM (1993) Production of fuel alcohol from wheat by VHG technology. Appl Biochem Biotechnol 43:211-226

5. Reeve $P(1998)$ Sweat your fermentation assets. Brewer 12:212-215

6. Bafrncova P, Smogrovicova D, Salvikova I, Patkova J, Domeny Z (1999) Improvement of very high gravity ethanol fermentation by media supplementation using Saccharomyces cerevisiae. Biotechnol Lett 21:337-341

7. Casey GP, Magnus CA, Ingledew WM (1984) High-gravity brewing: effects of nutrition on yeast composition, fermentative ability, and alcohol production. Appl Environ Microbiol 48:639-646

8. Alfenore S, Molina-Jouve C, Guillouet SE, Uribelarrea JL, Goma G, Benbadis L (2002) Improving ethanol production and viability of Saccharomyces cerevisiae by vitamin feeding strategy during fed batch process. App Microbiol Biotechnol 60:67-72

9. Damoano D, Wang SS (1985) Improvements in ethanol concentration and fermentor ethanol productivity in yeast fermentations using whole soy flour in batch and continuous recycle systems. Biotechnol Lett 71:35-140

10. Deepak S, Visvanathan L (1984) Effects of oils and fatty acids on the tolerance of distillers yeast to alcohol and temperature. Enzyme Microb Technol 6:78-80

11. Patil SG, Patil BG (1989) Chitin supplement speeds up the ethanol production in cane molasses fermentation. Enzyme Microb Technol 11:38-43

12. Patil SG, Patil BG, Gokhale VD, Bastawde KB, Puntambekar S, Ranjekar PK (2000) Process for the production of alcohol. US Patent no: 6016699.

13. Reddy LVA, Reddy OVS (2005) Improvement of ethanol production in very high gravity fermentation by horse gram (Dolichos biflorus) flour supplementation. Lett Appl Microbiol 41:440-445

14. Reddy LVA, Reddy OVS (2006) Rapid and enhanced production of ethanol in very high gravity (VHG) sugar fermentation by Saccharomyces cerevisiae: role of finger millet (Eleusinae coracana L.) flour. Process Biochem 41:726-729

15. Shaffer PA, Somogyi M (1933) Copper iodometric reagents for sugar determination. J Biol Chem 100:695-713

16. Antony JC (1984) Malt beverages and malt brewing materials: gas chromatographic determination of ethanol in beer. J Assoc Off Annal Chem 67:192-193

17. Aranda JS, Salgado E, Taillandier P (2004) Trehalose accumulation in Saccharomyces cerevisiae cells: experimental data and structured modeling. Biochem Eng J 17:129-140

18. Postgate JP (1967) Viable counts and viability. In: Norris JR, Ribbons DW (eds) Methods in microbiology, vol. 1. Academic Press, New York

19. Ferguson LR (2001) Role of plant polyphenols in genomic stability. Mutat Res 475:89-111

20. Li LL, Ye YR, Pan L, Zhu Y, Zheng S, Lin Y (2009) The induction of trehalose and glycerol in Saccharomyces cerevisiae in response to various stresses. BBRC 387:778-783

21. Klipp E, Nordlander B, Krüger R, Gennemark P, Hohmann S (2005) Integrative model of the response of yeast to osmotic shock. Nat Biotechnol 23:975-982

22. Da Costa M, Da Silva C, Mariani D, Fernandes P, Pereira M, Panek A, Eleutherio $E$ (2008) The role of trehalose and its transporter in protection against reactive oxygen species. Biochem Biophys Acta 1780:1408-1411

23. Siderius M, Van Wuytswinkel O, Reijenga K, Kelders M, Mager W (2000) The control of intracellular glycerol in Saccharomyces cerevisiae influences osmotic stress response and resistance to increased temperature. Mol Microbiol 36:1381-1390

24. Uesono $Y$, Tohe A (2002) Transient inhibition of translation initiation by osmotic stress. J Biol Chem 277:13848-13855

25. Lin YH, Chien WS, Duan KJ, Chang PR (2011) Effect of aeration timing and interval during very-high-gravity ethanol fermentation. Process Biochem 46:1025-1028

\section{doi:10.1186/s40643-014-0022-8}

Cite this article as: Lebaka et al:: Effect of fruit pulp supplementation on rapid and enhanced ethanol production in very high gravity (VHG) fermentation. Bioresources and Bioprocessing 2014 1:22.

\section{Submit your manuscript to a SpringerOpen ${ }^{\odot}$ journal and benefit from:}

- Convenient online submission

- Rigorous peer review

- Immediate publication on acceptance

- Open access: articles freely available online

- High visibility within the field

- Retaining the copyright to your article

Submit your next manuscript at $>$ springeropen.com 